\title{
Mechanical behavior and frost-resistance of alkali activated cement concrete with blended binder systems
}

\author{
Biruk Hailu Tekle ${ }^{1}$, Klaus Holschemacher ${ }^{1, *}$, Philipp Löber ${ }^{1}$ and Björn Heiden ${ }^{1}$
}

\author{
1 Structural Concrete Institute, Leipzig University of Applied Sciences (HTWK Leipzig), 04277 Leipzig, Ger- \\ many; birukh.tekle@gmail.com (B.H.T.); philipp.loeber@htwk-leipzig.de (P.L.); \\ bjoern.heiden@htwk-leipzig.de (B.H) \\ * Correspondence: klaus.holschemacher@htwk-leipzig.de
}

\begin{abstract}
Concrete is the most commonly used construction material due to its various advantages, such as versatility, familiarity, strength and durability and it will continue to be in demand far into the future. However, with today's sensitivity to the environmental protection, this material is facing unprecedented challenges due to its high greenhouse gas emission mainly during cement production. This paper investigates one of the promising cement replacement materials, alkali activated cement (AAC) concrete. Being produced mainly from byproduct materials and having a comparable structural performance to conventional concrete, AAC concrete has a potential to transform the construction industry. Mechanical properties such as compressive and flexural strength and the relationship between them are studied. Different source materials such as fly ash (FA), ground granulated blast furnace slag (GGBS), silica fume (SF) and Metakaolin (MK) are used. The effect of the source materials and the activator solutions on the concrete performance is studied. Furthermore, the freeze-thaw resistance of the concrete is studied. The results of the study showed that the behavior of AAC depends highly on the source material combinations as well as type used. The effect of the alkaline solution is also dependent on the source material used. Mixes with higher GGBS content in general showed the highest strength while mixes with MK showed the highest flexural strength. The results from the freeze-thaw test showed that proper design of AAC concrete with a lower water content is critical to achieve a good resistance.
\end{abstract}

Keywords: Alkali activated, Fly ash, Blast furnace slag, Silica fume, Metakaolin, Ambient curing, Strength development, flexural strength, Freeze-thaw resistance

\section{Introduction}

Concrete is the most commonly used construction material and due to its versatility, familiarity, strength, durability and more, and it will continue to be in demand far into the future. However, with today's sensitivity to environmental issues, this material is facing unprecedented challenges. This is especially related to its main binder, cement. Global cement production has increased more than 30-fold since 1950 and almost 4-fold since 1990 [1]. The production of cement requires combustion of limestone which releases $\mathrm{CO}_{2}$ into the atmosphere. Despite the various progressions made to improve the efficiency of the cement production, about a tone of $\mathrm{CO}_{2}$ is released for every tone of cement production [2]. The cement industry therefore contributes about $8 \%$ of the global $\mathrm{CO}_{2}$ emission [1]. This has led the scientific community to look for a binder with less environmental footprint.

Alkali activated cement (AAC) concrete is finding a momentum in the construction industry due to its environmental advantages and comparable structural performance to conventional concrete. AAC concrete is a concrete produced from industry byproduct materials such as fly ash and slag. It has highly desirable characteristics such as high strength, excellent fire resistance and acid resistance [3-6]. Most importantly, AAC is 
much more environmentally friendly than conventional concrete because of its zero cement consumption.

The behavior of AAC concrete depends on various parameters of the concrete mixture. One such parameter is the aluminosilicate source material used. Fly ash (FA), ground granulated blast furnace slag (GGBS), metakaolin (MK), silica fume (SF), rice husk ash (RHA) and other similar alumina and silica rich materials has been successfully used for AAC [7-9]. Due to the different chemical composition, fineness, particle shape and other material specific behaviors, the performance of AAC varies with the source material used. Even though there are various studies on the behavior and performance of the individual source materials [10-14], there are only limited researches on the performance of AAC concrete containing blended binder systems. Hadi et al [15] observed that the inclusion of FA, MK and SF as partial replacement of GGBS reduces the compressive strength while increasing the setting time and workability of AAC. Similarly Fang et al. [16] reported the decrease in workability and setting time with the increase of GGBS content in FA-GGBS based AAC concrete. Rajamma et al. [17] found adding MK to FA based mortar increased compressive strength. The results from these studies reveal that optimum design of concrete mixture is possible by mixing two or more source materials together. Understanding this potential, a research program was initiated at the structural concrete institute in order to study the effect of combinations of FA, GGBS, MK, SF and RHA. Both mechanical performance and durability aspect of the AAC concrete are studied. The effect of the mix proportion parameters on compressive and flexural strength and the relationship between them are studied. In terms of the durability, the freeze-thaw resistance is studied.

\section{Experimental Program}

\subsection{Materials}

Fly ash (FA), ground granulated blast furnace slag (GGBS), silica fume (SF), metakaolin (MK) and rice husk ash (RHA) were used as the source materials. Two types of SF, SF1 and SF2 and two types of MK, MK1 and MK2 were used. The chemical compositions of these source materials are summarized in Table 1 . The activator solution used is mixture of sodium silicate and sodium hydroxide. The sodium silicate solution includes $26.82 \%$ silicate, $8.2 \%$ sodium oxide and $64.98 \%$ water. The sodium hydroxide is a $50 \%$ by weight solution. Furthermore, a fine aggregate with a maximum aggregate size of $2 \mathrm{~mm}$ and a maximum coarse aggregate size of mainly $8 \mathrm{~mm}$ (in few cases $16 \mathrm{~mm}$ ) were used.

Table 1. Chemical compositions of source materials

\begin{tabular}{cccccccccc}
\hline $\begin{array}{c}\text { Component } \\
(\%)\end{array}$ & $\mathrm{SiO}_{2}$ & $\mathrm{Al}_{2} \mathrm{O}_{3}$ & $\mathrm{Fe}_{2} \mathrm{O}_{3}$ & $\mathrm{MgO}$ & $\mathrm{CaO}$ & $\mathrm{K}_{2} \mathrm{O}$ & $\mathrm{Na}_{2} \mathrm{O}$ & $\mathrm{SO}_{3}$ & $\begin{array}{c}\text { Average } \\
\text { particle size }(\mu \mathrm{m})\end{array}$ \\
\hline $\mathrm{FA}$ & 49.79 & 26.71 & 8.57 & 2.47 & 4.34 & 3.36 & 1.28 & 1.49 & - \\
$\mathrm{GGBS}$ & 34.48 & 11.48 & - & 7.08 & 42.43 & 0.66 & 0.56 & 2.17 & - \\
$\mathrm{MK} 1[18]$ & 54.4 & 27.1 & 1 & 0.7 & 4.5 & 2.3 & 7.9 & 0.3 & 14.9 \\
$\mathrm{MK} 2$ & 53.16 & 44.51 & 0.54 & - & - & - & - & - & $1.3^{*}$ \\
$\mathrm{SF} 1^{*}$ & 93.81 & 0.48 & 1.49 & 0.46 & 0.3 & 0.77 & 0.42 & 0.2 & - \\
$\mathrm{SF}^{*}$ & 96.05 & 1.11 & - & 0.46 & 0.72 & 1.2 & 0.46 & - & $0.15^{*}$ \\
$\mathrm{RHA}^{*}$ & 92 & 1 & 1 & 1 & 1 & 1 & 2 & 1 & 51.1 \\
\hline
\end{tabular}

* Manufacturer specification

The Scanning Electron Microscope (SEM) image of some of the source materials is as shown in Figure 1. 

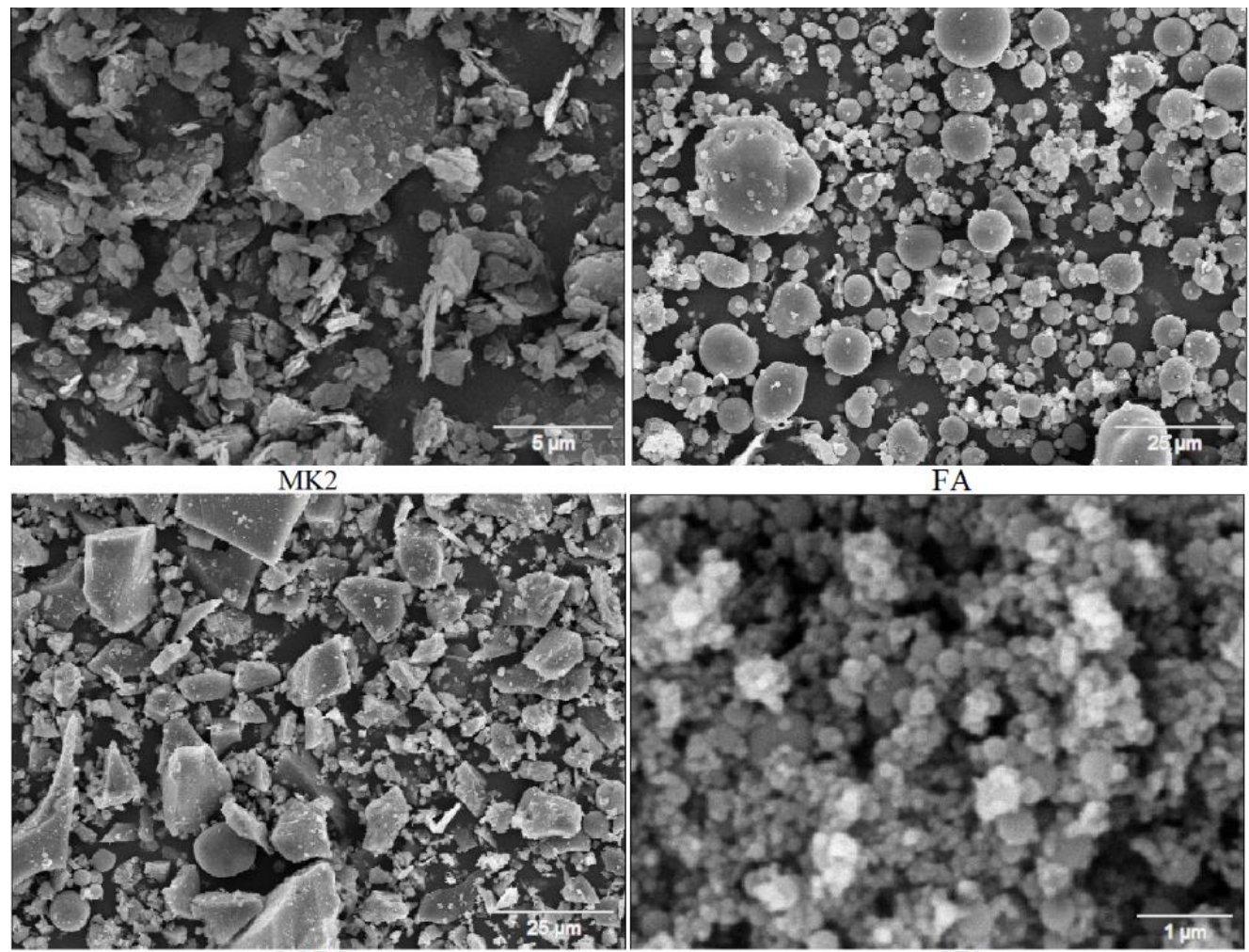

GGBS

$\mathrm{FA}$

Figure 1. SEM image of source materials

\subsection{Specimen preparations and test methods}

The sodium silicate and sodium hydroxide solutions were mixed together in the required proportion at least 24 hours prior to mixing. During mixing care was taken to keep the temperature below $40^{\circ} \mathrm{C}$ to prevent a deposition of the solution, which was observed when the temperature was higher. AAC specimens were prepared by first mixing the dry materials (sand and binder) together in a mixer for about two minutes. Afterwards, the prepared alkaline solution was mixed with the additional water and added slowly to the dry mixture and mixed for about four minutes. The freshly mixed concrete was then placed into $40 \mathrm{~mm} \times 40 \mathrm{~mm} \times 160 \mathrm{~mm}$ prisms or $150 \mathrm{~mm}$ cubes, in case of $16 \mathrm{~mm}$ aggregates, for compressive and flexural or splitting tensile strength tests. These specimens were cast in two layers and each layer was vibrated. After casting the specimens were left in the lab covered with plastic for the first 24 hours and then placed in water after demolding until test day. The compressive and flexural strengths of the prisms were measured according to DIN EN 196-1 [19]. The tests were carried out on the 7th and 28th days. Freeze-thaw resistance was tested according to DIN EN 12390-9 using the Capillary suction of deionized water and freeze thaw test (CIF) method. Two different mixes were investigated and for each mix five samples were tested. The scaled mass was measured at 14, 28, 42 and 56 cycles for each sample.

\subsection{Mix proportions}

In order to understand the influence of the mix proportion different AAC concrete mixtures were designed and tested. These mixes are divided into three main groups based on the main source material used, i.e. FA, GGBS and MK. In addition to the source material, the amount of the activator, the water content, and the type of the source material (different type of $\mathrm{MK}$ and SF) were also varied in order to understand their effect. The total source material content was kept at $400 \mathrm{~kg} / \mathrm{m}^{3}$, while the ratio of the sodium silicate and sodium hydroxide solutions was kept at 2.5. Table 2, 3 and 4 summarizes the mix proportions respectively for FA, GGBS and MK based concretes. In this table, AS/B means the ratio of the total alkaline solid to the total source materials while TW/TS means 
the ratio of the total water (water from the alkaline solutions and the free water) to the total solid in the binder system (solids from the alkaline solution plus the source materials).

Table 2. Details of mix proportions and results for FA based concretes

\begin{tabular}{ccccccc}
\hline Mix ID & AS/B & TW/TS & \multicolumn{2}{c}{ Compressive } & \multicolumn{2}{c}{ Flexural } \\
\cline { 4 - 7 } & & & 7-day & 28-day & 7-day & 28-day \\
\hline F63G37-1 & 0.21 & 0.43 & 34.65 & 54.74 & 4.69 & 6.64 \\
F63G37-2 & 0.26 & 0.43 & 34.48 & 52.90 & 4.62 & 6.52 \\
F63G37-3 & 0.21 & 0.50 & 23.43 & 31.61 & 4.51 & - \\
F63G37-4 & 0.21 & 0.44 & 36.82 & - & 4.51 & - \\
F63G37-5* & 0.21 & 0.26 & 46.19 & 64.32 & $3.21^{\mathrm{d}}$ & $3.74^{\mathrm{d}}$ \\
F80G20-6 & 0.21 & 0.35 & 20.54 & 39.19 & 3.72 & 6.64 \\
F80G20-7 & 0.25 & 0.35 & 25.04 & 43.03 & 4.40 & 6.25 \\
F80G20-8 & 0.28 & 0.35 & 35.70 & 51.81 & 5.32 & 6.95 \\
F37G37M26-9 & 0.26 & 0.46 & 26.66 & 42.46 & 4.09 & 5.59 \\
F35G35M30-10 & 0.26 & 0.46 & 27.86 & 51.32 & 4.76 & 7.10 \\
F35G35M25S5-11 & 0.25 & 0.42 & 30.57 & 45.35 & 4.63 & 6.03 \\
\hline
\end{tabular}

F- FA, G- GGBS, M- MK1, S-SF1, d-splitting tensile strength, ${ }^{*} 16 \mathrm{~mm}$ aggregate Size, F63G37 $-63 \% \mathrm{FA}$ and $37 \%$ GGBS, total binder $400 \mathrm{~kg} / \mathrm{m}^{3}$

Table 3. Details of mix proportions and results for GGBS based concretes

\begin{tabular}{|c|c|c|c|c|c|c|}
\hline \multirow[t]{2}{*}{ Mix ID } & \multirow[t]{2}{*}{ AS/B } & \multirow[t]{2}{*}{ TW/TS } & \multicolumn{2}{|c|}{ Compressive } & \multicolumn{2}{|c|}{ Flexural } \\
\hline & & & 7-day & 28-day & 7-day & 28-day \\
\hline G52M30S18-1 & 0.33 & 0.39 & 37.46 & 41.96 & 4.29 & 7.08 \\
\hline G52M30S18-2 & 0.29 & 0.39 & 41.14 & 56.84 & 5.66 & 6.80 \\
\hline G52M30S18-3 & 0.25 & 0.39 & 25.41 & 40.80 & 4.92 & 6.75 \\
\hline G52M30S18-4a & 0.33 & 0.39 & 47.64 & - & 5.71 & - \\
\hline G52M30S18-5b & 0.33 & 0.39 & 58.52 & 60.96 & 5.83 & 7.03 \\
\hline G52M30S18-6b & 0.26 & 0.43 & 36.86 & 50.99 & 5.83 & 7.41 \\
\hline G52M30R18-7 & 0.32 & 0.47 & 45.26 & 63.48 & 6.55 & 8.29 \\
\hline G52M30R18-8 & 0.26 & 0.49 & 41.46 & 64.14 & 5.68 & 8.88 \\
\hline G52M30R18-9 & 0.26 & 0.64 & 33.82 & - & 6.27 & - \\
\hline G52M30R18-10 & 0.19 & 0.54 & 15.07 & - & - & - \\
\hline G50M33R17-11* & 0.21 & 0.39 & 34.21 & 54.11 & $2.25^{\mathrm{d}}$ & $3.51^{\mathrm{d}}$ \\
\hline \multicolumn{7}{|c|}{$\begin{array}{l}\text { M- MK2, S- SF2, * } 16 \mathrm{~mm} \text { aggregate size and MK1, d-splitting tensile strength, a: SF1 } \\
\text { and MK1, b: SF1 and MK2 }\end{array}$} \\
\hline \multirow[t]{2}{*}{ Mix ID } & \multirow[t]{2}{*}{ AS/B } & \multirow[t]{2}{*}{ TW/TS } & \multicolumn{2}{|c|}{ Compressive } & \multicolumn{2}{|c|}{ Flexural } \\
\hline & & & 7-day & 28-day & 7-day & 28-day \\
\hline M75S25-1 & 0.39 & 0.43 & 29.53 & 35.04 & 4.82 & 6.38 \\
\hline M75S25-2 & 0.34 & 0.43 & 27.35 & 34.30 & 4.92 & 6.81 \\
\hline M75S25-3 & 0.31 & 0.47 & 25.47 & 29.30 & 4.33 & 5.70 \\
\hline M75S25-4 & 0.39 & 0.43 & 39.91 & 50.30 & 6.55 & 6.92 \\
\hline M75S25-5a & 0.39 & 0.43 & 2.60 & 6.31 & - & - \\
\hline M49G30R13S8-6a & 0.28 & 0.53 & 23.92 & 36.83 & 4.31 & 5.93 \\
\hline M44G44S12-7a & 0.28 & 0.48 & 28.22 & 40.79 & 4.56 & 5.74 \\
\hline M63G25S12-8a & 0.28 & 0.48 & 21.86 & 30.26 & 4.22 & 6.42 \\
\hline
\end{tabular}

M- MK2, S- SF2, a: SF1 and MK1, b: SF1 and MK2 
As workability of concrete is of high importance when it comes to application, the mixes were targeted at getting a good workability in the range of F4 and F5 according to DIN EN 206 [20]. Figure 2 shows G50M33R17-11 mix during workability assessment.
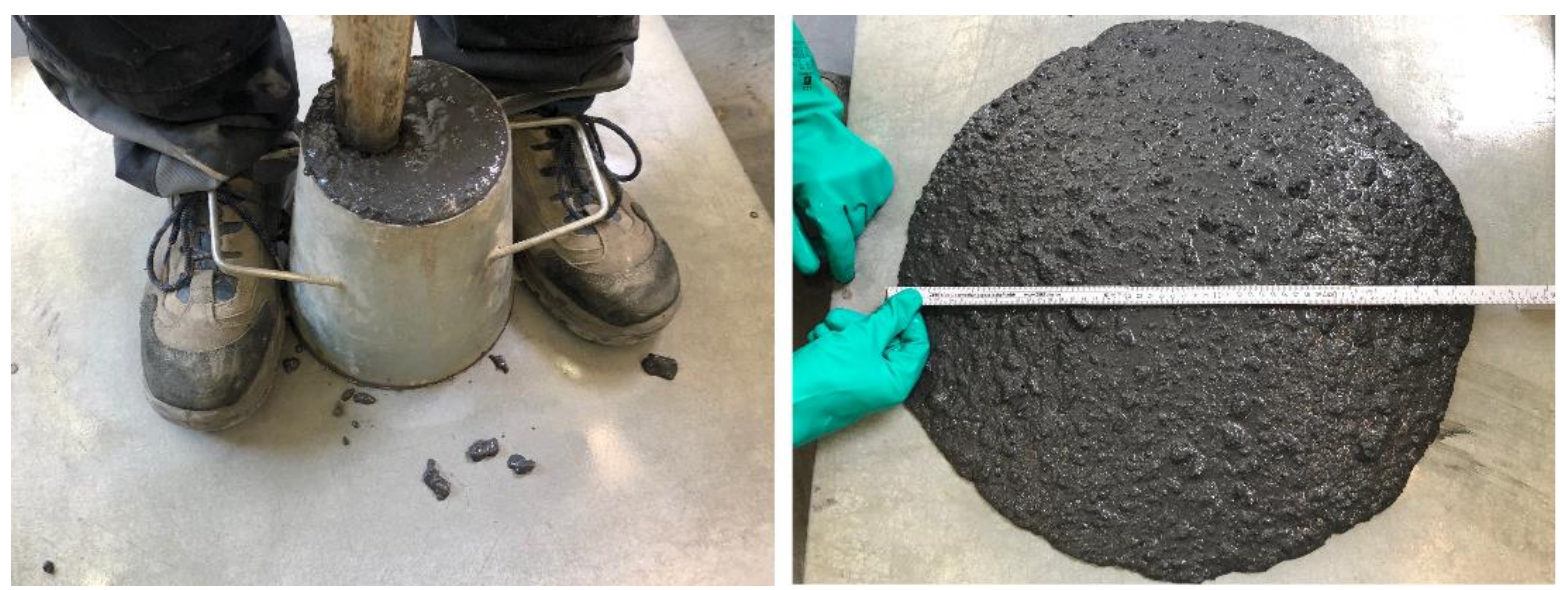

Figure 2. G50M33R17-11 during workability test

\section{Results and discussions}

The experimental program results for 7-day and 28-day compressive strength and flexural strength are summarized in the mix design tables, Table 2, 3 and 4 . The following sections present the analysis and discussion on the results.

\subsection{Effect of parameters}

The water content and the alkaline to binder ratios were varied in addition to the source materials and the type of source materials. The water content, investigated by TW/TS ratio, in general has a negative effect on the strength of the concrete. This is due to the porous structure the water leaves after evaporation. The effect of the alkaline content, which was investigated by AS/B ratio, was found to be dependent on the type of source material used. The influence of source material and alkaline content are investigated in detail in the following section.

\subsubsection{Effect of source material}

From the FA, GGBS and MK based mixes, the GGBS based mixes resulted in the highest strength. For instance, G52M30R18-8 with $0.26 \mathrm{AS} / \mathrm{B}$ and $0.49 \mathrm{TW} / \mathrm{TS}$ resulted in a 7- and 28-day strength of 41.46 and $64.14 \mathrm{MPa}$, respectively while F63G37-2 with the same AS/B and 0.43 TW/TS resulted in 34.48 and 52.90 MPa. The higher strength of G52M30R18-8 despite its higher water content shows the influence of GGBS on the strength. The effect of GGBS can also be observed by comparing mix F63G37-1 and F80G20-6. Mix F63G37-1 showed higher strength than mix F80G20-6 despite its higher TW/TS ratio, the main cause being its higher GGBS content. This is due to the high $\mathrm{CaO}$ content of GGBS. An increase in $\mathrm{CaO}$ content leads to mixed phases of aluminosilicate polymer networks and hydrate phases such as calcium silicate hydrates (C-S-H)-phases $[21,22]$. Depending on the $\mathrm{CaO}$ content, the reaction products can be dominated by either aluminosilicate network or C-S-H. A CaO content between 20-40\% leads to mixed system and over $40 \%$ leads to C-S-H dominated reaction products [23]. The higher the $\mathrm{CaO}$ content results in improved mechanical properties such as high early strength and final strength which is observed in the mixes with GGBS in this study [21]. The incorporation of MK is also another reason for the higher strength of mixes with GGBS and MK as in G52M30S18 mixes. The $\mathrm{MK}$ is reach in $\mathrm{Al}_{2} \mathrm{O}_{3}$ which in general has a positive effect on strength $[24,25]$.

Two types of MK, MK1 and MK2, were used. Mixes with MK2 resulted in a higher strength. This can be observed by comparing mix M75S25-4 and 5. Here mix M75S25-5 
with MK1 has a very low compressive strength. The mix was still in the plastic state after 24 hours showing the slow development of compressive strength. Mix M75S25-4 with MK2 on the other hand resulted in a much higher compressive strength. The effect of MK2 can also be observed by comparing G52M30S18-4 and 5, were the use of MK2 in case of G52M30S18-5 resulted in a higher strength. MK2 has a considerably smaller average particle size as can be observed in Table 1 resulting in an enhanced reactivity, hence a better strength. Furthermore, MK2 also has a high amount of $\mathrm{Al}_{2} \mathrm{O}_{3}$ compared to MK1. Higher $\mathrm{Al}_{2} \mathrm{O}_{3}$ increase the compressive strength of metakaolin based geopolymer concrete as reported by Kuoamo [24]. Hence, the higher $\mathrm{Al}_{2} \mathrm{O}_{3}$ could also be another reason for the higher strength of mixes with MK2.

Two types of SF were used, SF1 and SF2. As can be observed from G52M30S18-1 and G52M30S18-5 mixes, SF1 resulted in a higher strength than those with SF2 and the combination of SF1 and MK2 (G52M30S18-5) resulted in the highest strength of all the mixes investigated in this study. In terms of chemical composition, SF1 and SF2 show no significant difference. The higher performance of SF1 could be from other factors such as fineness, morphology or reactivity.

Source materials are critical factors on the performance of AAC concrete. In addition to the proportion of the source materials, the type of the source materials also significantly affects the behavior of the concrete. This is so because different types of the same class of source materials can have different physical and chemical behaviors.

\subsubsection{Effect of alkaline solution}

The binder content and the silicate to hydroxide solutions ratio are kept constant at $400 \mathrm{~kg} / \mathrm{m}^{3}$ and 2.5, respectively. The only variables in addition to the type and proportion of the source materials are the AS/B and the TW/TS ratios. The TW/TS ratio has a mainly negative effect on the strength due to the void spaces the water leaves after the reaction. The AS/B ratio on the other hand didn't show a consistent trend. This is because the effect of this ratio depends on the type of source material used as well as the value of the ratio. Different source materials are known to consume different amount of alkali [26]. At lower AS/B ratios, the strength increases with the increase of the ratio however after an optimum level for that specific source material is attained strength decreases with the increase of the ratio [27,28]. In G52M30S18-1 to 3 mixes for instance the compressive strength first increased when the AS/B increased from 0.25 to 0.29 and then decreased as AS/B further increased to 0.33. In case of F63G37 mixes the increase of AS/B ratio from 0.21 to 0.26 resulted in a slight decrease in the strength of the concrete. However, for F80G20-6 to 8 mixes, the increase in the AS/B ratio from 0.21 to 0.25 and further to 0.28 increased both the 7 days and 28 days strengths showing that the AS/B required varies depending on the source material. Such behaviors were also observed by Samson et al. [26].

\subsection{Strength development}

Strengths were measured at 7 and 28 days. The strength development over this period, i.e. the ratio of the 28-day strength to the 7-day strength has been found to vary with the type of the source materials used. In case of mixes with GGBS, this ratio increased as the percent of GGBS decreased. For instance, in case of FA and GGBS mixes, a 20\% GGBS as in F80G20 resulted in an average ratio of 1.69 while a 37\% GGBS as in F63G37 resulted a lower ratio of 1.49. In case of G52M30S18 mixes, a higher GGBS percentage was used and this resulted in an even lower ratio of 1.31 meaning a higher early strength as can be observed from Table 3. A high early strength was also observed by Samson et al. [26] in case of MK-GGBS mixes. In case of M75S25 mixes, a ratio of 1.22 was found.

GGBS has the highest $\mathrm{CaO}$ content compared to all the other source materials as can be observed in Table 1 . The high $\mathrm{CaO}$ content increases the early formation of calcium silicate hydrate (C-S-H) in addition to aluminosilicate polymer networks resulting in a mixed phase hydrates and aluminosilicates [21,22]. This in turn results in a higher early age strength. Hence the concrete in case of high GGBS attains its strength early resulting 
in lower 28-day to 7-day strength ratio. The high $\mathrm{Al}_{2} \mathrm{O}_{3}$ content of $\mathrm{MK}$ can also facilitate the early reaction between the source materials and the alkaline solution resulting in a higher early strength hence a lower strength ratio as in the case of GGBS.

The AS/B ratio also affected the strength development. The increase of AS/B, as can be observed in mixes G52M30S18-1 to 3 significantly reduced the 28-day to 7-day strength ratio. Similar trends can be observed for F80G20-6 to 8 and M75S25-1 and 2 mixes. This is because a high activator content facilitates early dissolution of the source materials resulting in a high early strength. A higher water content can also facilitate the dissolution of the source materials resulting in a higher relative early age strength and a lower ratio of 28-day to 7-day strength. This can be observed by comparing F63G37-1 and 3 as well as G52M30-3 and 8. In case of F63G37 for instance, at the same AS/B ratio the TW/TS ratio increased from 0.43 to 0.50 and respective strength ratio deceased from 1.58 to 1.35 .

\subsection{Flexural strength}

Flexural strength of concrete is another important mechanical property which represent the ability of the material to resist bending. It is highly related to compressive strength of the concrete. Various standards give recommendation on the relationship between the flexural strength and compressive strength for OPC concrete. In this study, the ACI 318, AS 3600 and EC 2 are used to predict the flexural strength of ambient cured AAC concrete [29-31].

ACI 318 recommends Eq. (1) as the relationship between flexural strength $\left(f_{c t, f}\right)$ and characteristic cylinder compressive strength $\left(f_{c}^{\prime}\right)$. The relationship between the characteristic strength and the mean compressive strength $\left(f_{c m}\right)$ are given by Eq. $(2-4)$. In all the following equations, Eq. (1-12), stress is in MPa and length in $\mathrm{mm}$.

$$
\begin{gathered}
f_{c t, f}=0.62 \sqrt{f_{c}^{\prime}} \\
f_{c}^{\prime}=f_{c m}-7(\mathrm{MPa}) \text { for } f_{c}^{\prime}<21 \mathrm{MPa} \\
f_{c}^{\prime}=f_{c m}-8.3(\mathrm{MPa}) \text { for } 21<f_{c}^{\prime} \leq 35 \mathrm{MPa} \\
f_{c}^{\prime}=\left(f_{c m}-5.0(\mathrm{MPa})\right) / 1.1 \text { for } f_{c}^{\prime}>35 \mathrm{MPa}
\end{gathered}
$$

AS 3600 uses Eq. (5) to calculate the characteristic flexural strength $\left(f_{c t . f}^{\prime}\right)$ of concrete. The mean value of the flexural strength as per this standard is determined by multiplying the characteristic value with 1.4. The relationship between the mean compressive strength and the characteristic strength are given by Eq. (6) for a concrete grade in the range of 25 to $65 \mathrm{MPa}$.

$$
\begin{gathered}
f_{c t . f}^{\prime}=0.6 \sqrt{f_{c}^{\prime}} \\
f_{c}^{\prime}=0.9 f_{c m}-3(M P a)
\end{gathered}
$$

For characteristic cylinder strength less than $50 \mathrm{MPa}$, EC 2 recommends Eq. (7) to calculate the flexural strength from the mean axial tensile strength $\left(f_{c t m}\right)$, where $h$ is the total depth of the flexural specimen in $\mathrm{mm}(40 \mathrm{~mm})$ and $f_{c t m}$ as per the same standard is given by Eq. (8). For characteristic strengths greater than $50 \mathrm{MPa}$, the standard recommends Eq. (9). The relationship between the mean compressive strength and the characteristic strength are given by Eq. (10).

$$
\begin{gathered}
f_{c t, f}=\max \left\{\left(1.6-\frac{h}{1000}\right) f_{c t m} ; f_{c t m}\right\} \\
f_{c t m}=0.3 f_{c}^{\prime 2 / 3}
\end{gathered}
$$




$$
\begin{gathered}
f_{c t m}=2.12 \cdot \ln \left(1+\left(\frac{f_{c m}}{10}\right)\right) \\
f_{c}^{\prime}=f_{c m}-8
\end{gathered}
$$

Diaz-Loya [32] and Nath and Sarker [33] developed empirical equations for AAC concrete by calibrating experimental results. Diaz-Loya [32] developed Eq. (11) for heat cured AAC concrete while Nath and Sarker [33] developed Eq. (12) for ambient cured AAC concrete.

$$
\begin{gathered}
f_{c t, f}=0.69 \sqrt{f_{c m}} \\
f_{c t, f}=0.93 \sqrt{f_{c m}}
\end{gathered}
$$

Using cube to cylinder conversion factor of 0.82 , based on average value from EC 2, all the equations were converted to flexural strength as a function of cube compressive strength. The resulting relationship for cube compressive strength vs flexural strength is as shown in Figure 3 (additional results from trial mixes are also used in developing these relationships).
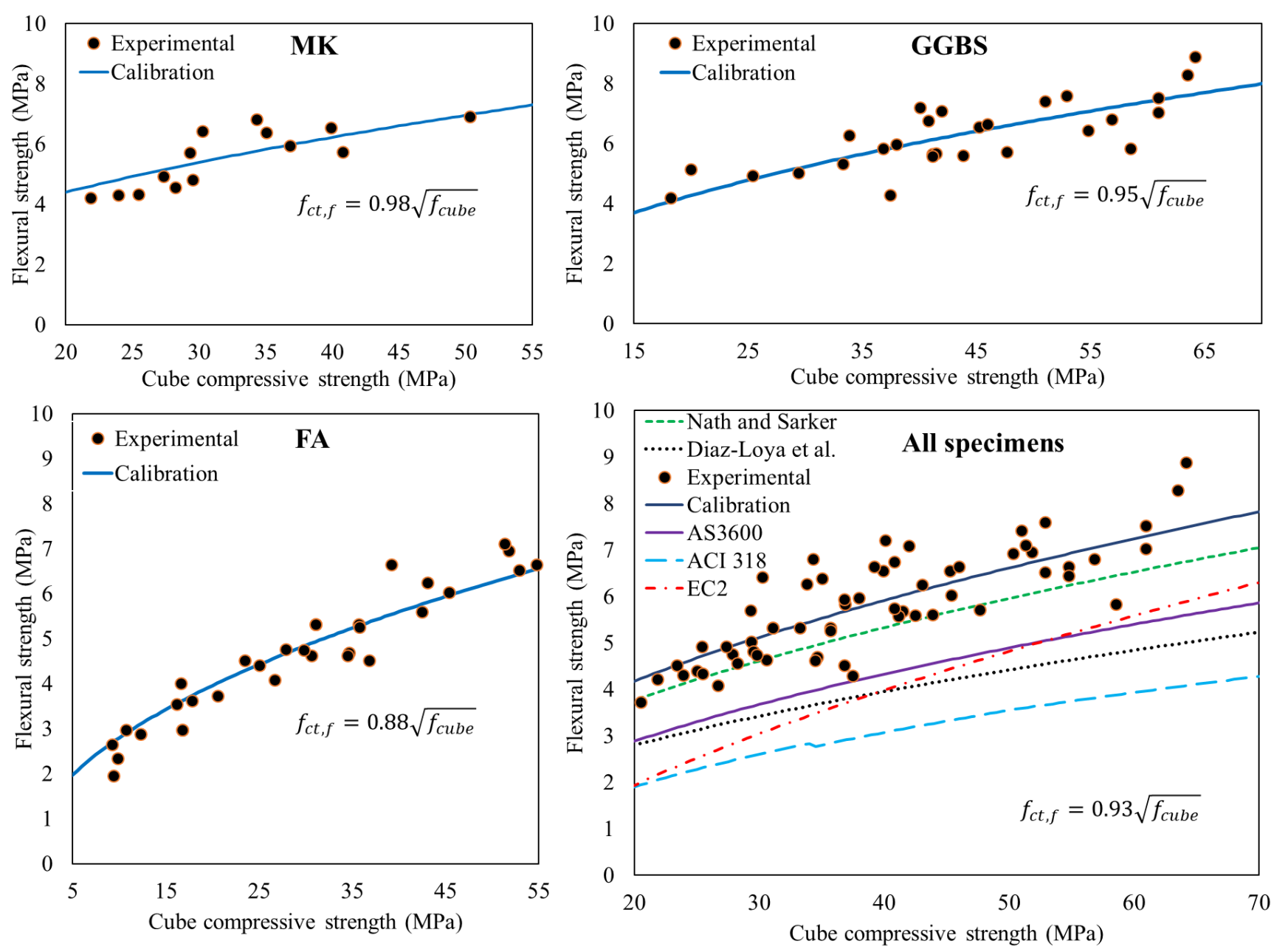

Figure 3. Comparison of experimental and predicted flexural strengths

As can be observed in Figure 3, the experimental values of the flexural strength are higher than the predicted values for all the standards investigated. From the standards, AS 3600 resulted in a better prediction of the flexural strength. The equation developed for heat cured concrete underpredicted the flexural strength of the ambient cured AAC in this study. It showed a better performance compared to the ACI 318 standard but the AS 3600 and EC 2 performed better. Eq. (12) was found to be the best performing one. 
A least square optimization was also performed on the experimental results for each of the MK, GGBS and FA based mix and for all the mixes together. As can be seen in Figure 3, a variation was observed on the calibration coefficient between the different mix types. MK based mixes resulted in the highest flexural strength which is approximately the square root of the cube compressive strength. The FA based mixes on the other hand resulted in the lowest flexural strength which is about 0.88 times the square root of the cube compressive strength. This could be due to the particle shape of the source materials. MK as can be seen in Figure 1 has a plate-like morphology while FA has a spherical morphology. Eq. (12) when converted to cube strength has a coefficient of 0.84 . This is close to the FA based mixes than the other mixes. This is because the mixes in Nath and Sarker [33] are FA based concretes, with minimum 85\% FA and maximum 15\% GGBS.

\subsection{Freeze-thaw resistance}

The durability problems of concrete in cold weather can generally be an internal cracking due to freezing and thawing cycles and surface scaling due to freezing in the presence of de-icing salts [34]. These problems depend on the porous network of the materials. The porous nature of AAC like OPC makes them susceptible to frost attack. Due to the limited researches available on the topic and the different types of AAC it is difficult to make a conclusive remark on the frost resistance of AAC. Bilek et al. [35] reported that the frost resistance of AAC can in general be considered as good. Fu et al. [36] reported the excellent freeze-thaw resistance of Alkali activated slag concrete. On the other hand, Coppola et al. [37] reported the lower freeze-thaw resistance of one-part alkali activated slag-based mortars compared to Portland cement mortars.

The frost resistance of AAC like OPC depends on the type of binder used and the various mix proportion parameters of the concrete [38]. Sodium silicate is reported to have a better frost resistance than other activators such as sodium carbonate [34,39]. Cai et al [40] on their study on freeze-thaw resistance of alkali-slag concrete found that activator to slag ratio and slag content are the most prominent factors affecting freeze-thaw resistance. Addition of nano particles such as silica, alumina and clay have been reported to improve the freeze-thaw resistance of AAC [41,42].

In this study freeze-thaw resistance was tested according to DIN EN 12390-9 using the Capillary suction of deionized water and freeze thaw test (CIF) method. Two mixes i.e., F63G37-5 and G50M33R17-11 were tested. For each mix five samples were tested. The scaled mass was measured at 14, 28, 42 and 56 cycles for each sample. Table 5, shows the average total scaled mass for each of the specimen at different cycles. Figure 4 shows some of the specimens at the 14 and 56 freeze-thaw cycles for both F63G37-5 and G50M33R17-11 mixes.

Table 5. Freeze-thaw resistance

\begin{tabular}{cccc}
\hline Mixture & Cycles & Average & St. D \\
\hline F63G37-5 & 14 & 0.476 & 0.119 \\
& 28 & 0.726 & 0.104 \\
& 42 & 0.892 & 0.089 \\
G50M33R17-11 & 56 & 0.999 & 0.073 \\
& 14 & 0.839 & 0.368 \\
& 28 & 2.145 & 0.467 \\
& 42 & 3.715 & 0.166 \\
& 56 & 4.618 & 0.262 \\
\hline
\end{tabular}

Figure 5 shows the weight loss as a function of the freeze-thaw cycle. As can be observed in this figure, Mix F63G37-5 performed much better at any of the cycles. To understand this, it is important to understand the behavior of each of the mix. F63G37-5 mix uses only FA and GGBS as the source material and has a 28 days compressive strength of $64 \mathrm{MPa}$. G50M33R17-11 on the other hand uses GGBS, FA, MK and RHA and has a 
higher water content than F63G37-5 resulting a lower 28-day compressive strength of 54 MPa. The higher water content of G50M33R17-11 is believed to be the main cause of its lower performance. Mix F63G37-5 has a TW/TS ratio of 0.26 while G50M33R17-11 has 0.39 . For non-air-entrained concretes a water to binder ratio of less than 0.3 are usually needed to reach an acceptable level of durability [34]. This explains the difference in freeze-thaw resistance between the two mixes. Winnefeld et al. [43] in their study with GGBS based and FA based AAC reported that higher strength mixes offer a better freeze-thaw resistance for both types of AACs.

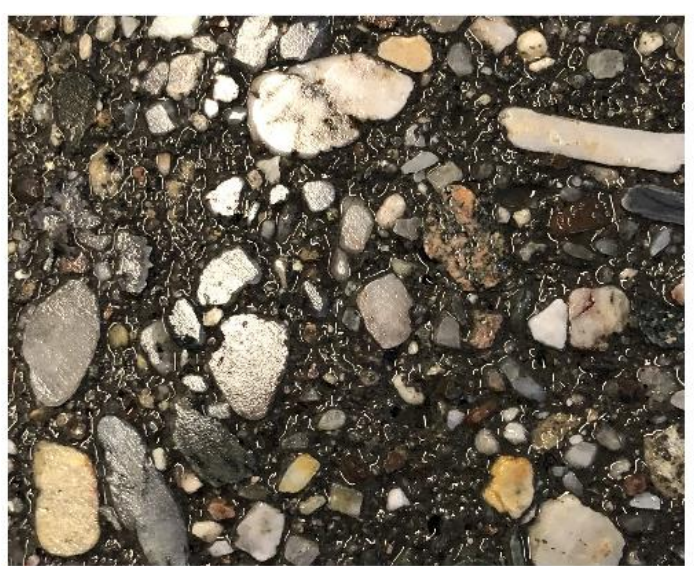

F63G37-5 14 cycles

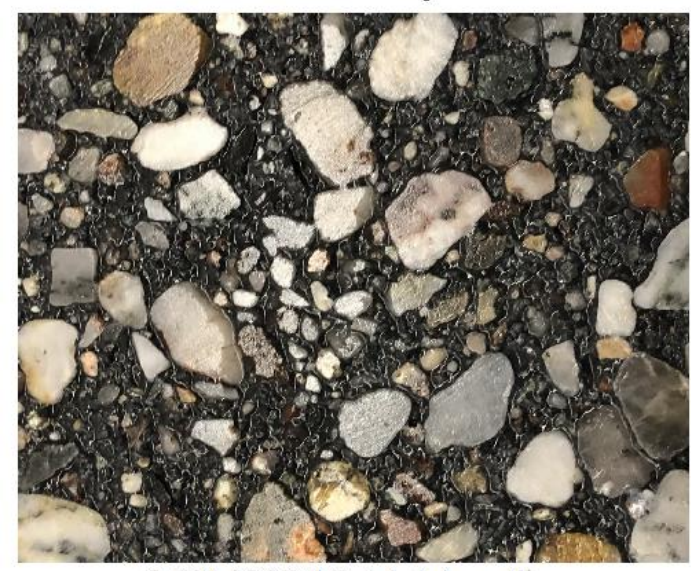

G50M33R17-11 14 cycles

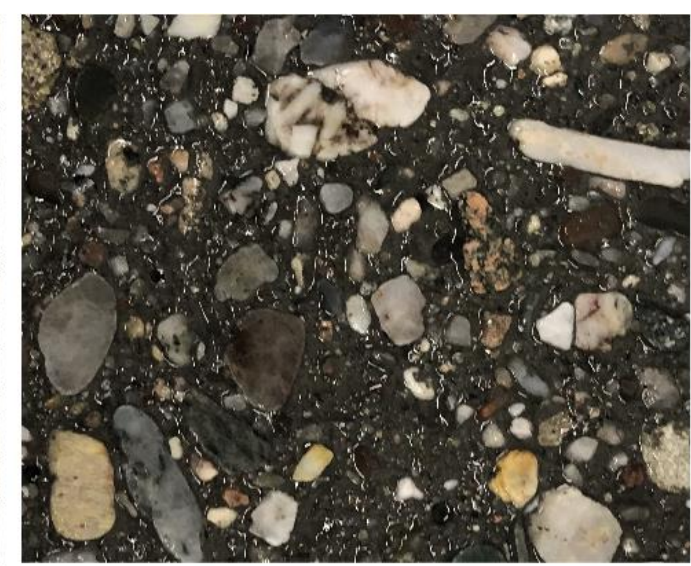

F63G37-5 56 cycles

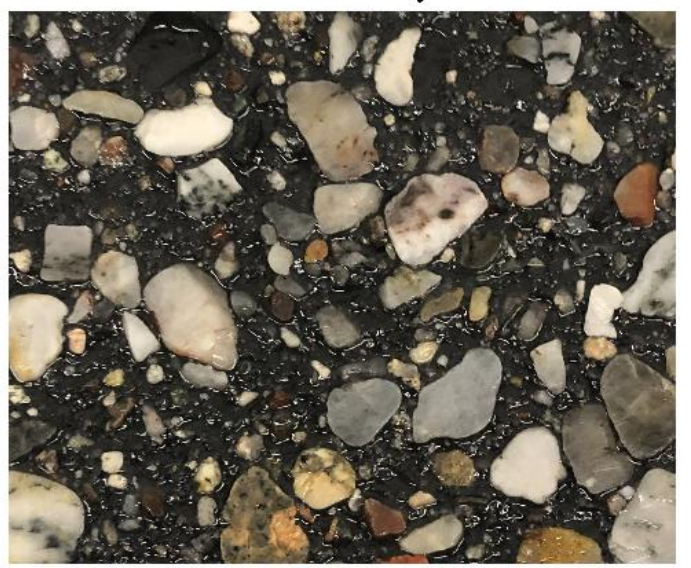

G50M33R17-11 56 cycles

Figure 4. Freeze-thaw specimens' surface after 14 and 56 cycles

Setzer and Auberg [44] in their study of scaling test found that all concretes meeting strictly all the design specifications of standards have a mean scaling below $1.5 \mathrm{~kg} / \mathrm{m}^{2}$ at 28 cycles, hence they recommended this value to classify a high freeze-thaw resistance concrete. Mix F63G37-5 meets this requirement with a scaling of $0.7 \mathrm{~kg} / \mathrm{m}^{2}$ at 28 freeze-thaw cycles and even at 56 cycles with about $1.0 \mathrm{~kg} / \mathrm{m}^{2}$ scaling. Mix G50M33R17-11 on the contrary has a scaling factor of $2.1 \mathrm{~kg} / \mathrm{m}^{2}$ at 28 cycles hence doesn't meet the requirement. 


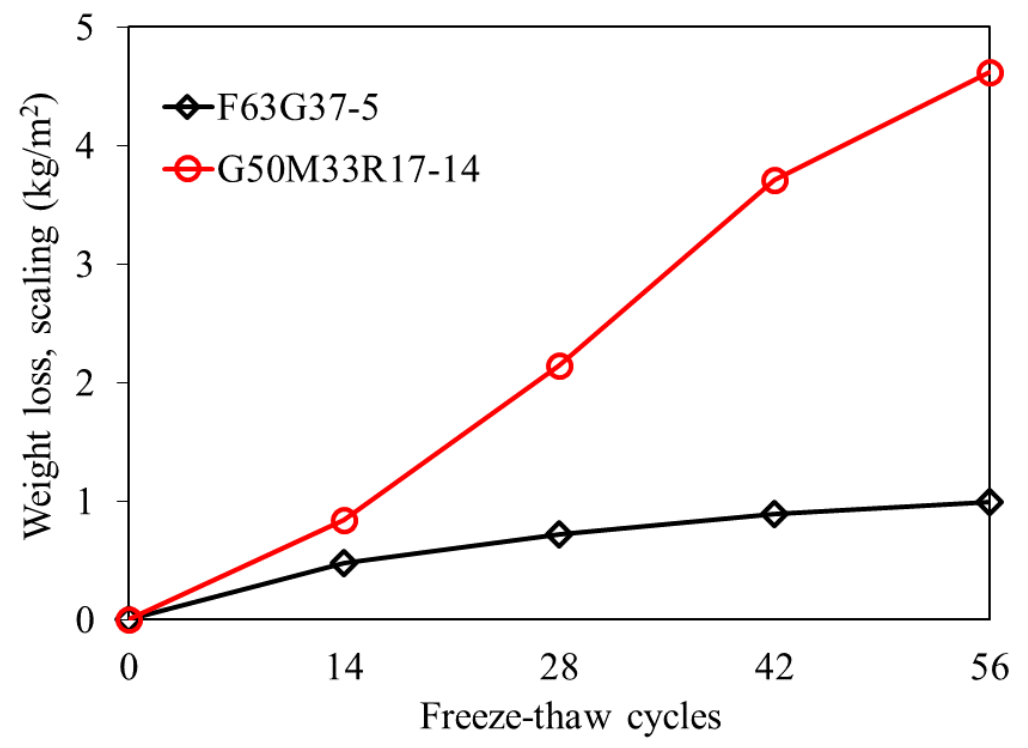

Figure 5. Mean scaling during freeze-thaw cycles

As observed from the freeze-thaw results in this study, with proper designing of AAC mixtures with lower TW/TS, AAC concrete with good freeze-thaw resistance can be prepared. Hence, as in the case of OPC concrete, the mix design of AAC concrete is also critical on their freeze-thaw resistance. Furthermore, AAC concretes with lower freeze-thaw resistance performance can be improved by using air entraining agents [34,37]. These admixtures improve the freeze-thaw resistance by enhancing the air-void networks. EN 206-1 [20] recommends 4.0\% vol. air content for XF2 to XF4 exposure classes.

\section{Conclusions}

Based on the experimental results presented in this study, the following conclusions can be drawn:

- The performance of AAC depends on both the relative proportion of the source materials and the type of source material used. Mixes with high $\mathrm{CaO}$ and $\mathrm{Al}_{2} \mathrm{O}_{3}$ content result in a higher strength.

- The effect of the alkaline solid to binder ratio depends on the source material used as well as the value of the ratio. Strength increases until an optimum ratio is reached and then it decreases.

- Mixes with high amount of GGBS and MK resulted in high early age strength while mixes with high FA developed their strength at a slower rate.

- The flexural strength of AAC concrete showed good correlation with the square root of the compressive strength. MK based mixes showed the highest flexural to compressive strength ratio.

- The results from the freeze-thaw test showed that it is possible to design a frost resistance AAC concrete mixture.

Author Contributions: “Conceptualization, P.L., B.H. and K.H.; methodology, P.L. and B.H.; formal analysis, B.H.T.; investigation, B.H.T.; data curation, B.H.T.; writing-original draft preparation, B.H.T.; writing - review and editing, B.H.T., P.L and K.H.; visualization, B.H.T.; supervision, K.H.; project administration, K.H. and P.L.; funding acquisition, K.H. and P.L. All authors have read and agreed to the published version of the manuscript.

Funding: This research was funded by German Federal Ministry for Economic Affairs and Energy as part of the ZIM-Project (ZF4007605KI7) and Alexander von Humboldt Foundation.

Conflicts of Interest: The authors declare no conflict of interest. 


\section{References}

[1] Andrew RM. Global CO2 emissions from cement production. Earth Syst. Sci. Data 2018;10(1):195-217. https://doi.org/10.5194/essd-10-195-2018.

[2] Garcia-Lodeiro, I., Palomo, A. \& Fernández-Jiménez, A. (ed.). Handbook of Alkali-Activated Cements, Mortars and Concretes. Elsevier; 2015.

[3] Juenger M, Winnefeld F, Provis JL, Ideker JH. Advances in alternative cementitious binders. Cement and Concrete Research 2011;41(12):1232-43. https://doi.org/10.1016/j.cemconres.2010.11.012.

[4] Bakharev T, Sanjayan J, Cheng Y-B. Resistance of alkali-activated slag concrete to acid attack. Cement and Concrete Research 2003;33(10):1607-11. https://doi.org/10.1016/S0008-8846(03)00125-X.

[5] Xie T, Visintin P, Zhao X, Gravina R. Mix design and mechanical properties of geopolymer and alkali activated concrete: Review of the state-of-the-art and the development of a new unified approach. Construction and Building Materials 2020;256:119380. https://doi.org/10.1016/j.conbuildmat.2020.119380.

[6] Pacheco-Torgal F, Abdollahnejad Z, Camões AF, Jamshidi M, Ding Y. Durability of alkali-activated binders: A clear advantage over Portland cement or an unproven issue? Construction and Building Materials 2012;30:400-5. https://doi.org/10.1016/j.conbuildmat.2011.12.017.

[7] John L. Provis, Angel Palomo, Caijun Shi. Advances in understanding alkali-activated materials. Cement and Concrete Research 2015;78:110-25. https://doi.org/10.1016/j.cemconres.2015.04.013.

[8] Provis JL, van Deventer JSJ. Geopolymers: Structure, processing, properties and industrial applications / edited by John L. Provis, Jannie S. J. van Deventer. Boca Raton, Fla.: CRC; Oxford Woodhead; 2009.

[9] Davidovits J. Geopolymer: Chemistry and applications. 5th ed. Saint-Quentin, France: Institut Géopolymère; 2020.

[10] Xiaolu Guo, Huisheng Shi, Warren A. Dick. Compressive strength and microstructural characteristics of class C fly ash geopolymer. Cement and Concrete Composites 2010;32(2):142-7. https://doi.org/10.1016/j.cemconcomp.2009.11.003.

[11] J. Temuujin, A. van Riessen, K.J.D. MacKenzie. Preparation and characterisation of fly ash based geopolymer mortars. Construction and Building Materials 2010;24(10):1906-10. https://doi.org/10.1016/j.conbuildmat.2010.04.012.

[12] Kim YY, Lee B-J, Saraswathy V, Kwon S-J, Wu Y. Strength and Durability Performance of Alkali-Activated Rice Husk Ash Geopolymer Mortar. The Scientific World Journal 2014;2014:209584. https://doi.org/10.1155/2014/209584.

[13] Chen L, Wang Z, Wang Y, Feng J. Preparation and Properties of Alkali Activated Metakaolin-Based Geopolymer. Materials (Basel) 2016;9(9). https://doi.org/10.3390/ma9090767.

[14] Hardjito, D., Rangan, B.V. Development and properties of low-calcium fly ash-based geopolymer concrete. Curtin University of Technology; 2005.

[15] Hadi MN, Farhan NA, Sheikh MN. Design of geopolymer concrete with GGBFS at ambient curing condition using Taguchi method. Construction and Building Materials 2017;140:424-31. https://doi.org/10.1016/j.conbuildmat.2017.02.131.

[16] Guohao Fang, Wing Kei Ho, Wenlin Tu, Mingzhong Zhang. Workability and mechanical properties of alkali-activated fly ash-slag concrete cured at ambient temperature. Construction and Building Materials 2018;172:476-87. https://doi.org/10.1016/j.conbuildmat.2018.04.008.

[17] Rejini Rajamma, João A. Labrincha, Victor M. Ferreira. Alkali activation of biomass fly ash-metakaolin blends. Fuel 2012;98:265-71. https://doi.org/10.1016/j.fuel.2012.04.006. 
[18] Ludwig H, Egersdörfer A, Trümer A. Leistungsfähigkeit von Metapor@ als Kompositmaterial im Zement Zement- und Betoneigenschaften; 2013.

[19] DIN EN 196-1:2016-11, Prüfverfahren für Zement_- Teil_1: Bestimmung der Festigkeit; Deutsche Fassung EN_196-1:2016. Berlin: Beuth Verlag GmbH. https://doi.org/10.31030/2482416.

[20] DIN EN 206. Concrete - Specification, performance, production and conformity 2017.

[21] Herrmann A, Koenig, A., Dehn, F. Proposal for the classification of alkali-activated binders and Geopolymer binders: Vorschlag zur Klassifizierung von alkalisch-aktivierten Bindemitteln und Geopolymeren. Cement International 2015;13.

[22] Herrmann A, Koenig A, Dehn F. Structural concrete based on alkali-activated binders: Terminology, reaction mechanisms, mix designs and performance. Structural Concrete 2018;19(3):918-29. https://doi.org/10.1002/suco.201700016.

[23] Buchwald A. The influence of calcium on the conden- sation of (alumino-) silicates in alkali-activated binders: (in German: Der Einfluss des Kalziums auf die Konden- sation von (Alumo-)Silikaten in alkali-aktivierten Bind- ern) [Habilitationsschrift]. Weimar: der Bauhaus-Universität Weimar; 2012.

[24] H. Tchakoute Kouamo, A. Elimbi, J.A. Mbey, C.J. Ngally Sabouang, D. Njopwouo. The effect of adding alumina-oxide to metakaolin and volcanic ash on geopolymer products: A comparative study. Construction and Building Materials 2012;35:960-9. https://doi.org/10.1016/j.conbuildmat.2012.04.023.

[25] Alanazi H, Hu J, Kim Y-R. Effect of slag, silica fume, and metakaolin on properties and performance of alkali-activated fly ash cured at ambient temperature. Construction and Building Materials 2019;197:747-56. https://doi.org/10.1016/j.conbuildmat.2018.11.172.

[26] Samson G, Cyr M, Gao XX. Formulation and characterization of blended alkali-activated materials based on flash-calcined metakaolin, fly ash and GGBS. Construction and Building Materials 2017;144:50-64. https://doi.org/10.1016/j.conbuildmat.2017.03.160.

[27] Li L, Lu J-X, Zhang B, Poon C-S. Rheology behavior of one-part alkali activated slag/glass powder (AASG) pastes. Construction and Building Materials 2020;258:120381. https://doi.org/10.1016/j.conbuildmat.2020.120381.

[28] Atiş CD, Görür EB, Karahan O, Bilim C, İlkentapar S, Luga E. Very high strength (120MPa) class F fly ash geopolymer mortar activated at different $\mathrm{NaOH}$ amount, heat curing temperature and heat curing duration. Construction and Building Materials 2015;96:673-8. https://doi.org/10.1016/j.conbuildmat.2015.08.089.

[29] ACI 318-19. ACI 318-19 Building Code Requirements for Structural Concrete and Commentary.

[30] AS 3600. Concrete structures 2018.

[31] EC 2. EN 1992-1-1: Design of concrete structures - Part 1-1: General rules and rules for buildings 2004.

[32] Diaz-Loya EI, Allouche EN, Vaidya S. Mechanical Properties of Fly-Ash-Based Geopolymer Concrete. ACI Materials Journal 2011;108(3). https://doi.org/10.14359/51682495.

[33] Nath P, Sarker PK. Flexural strength and elastic modulus of ambient-cured blended low-calcium fly ash geopolymer concrete. Construction and Building Materials 2017;130:22-31.

https://doi.org/10.1016/j.conbuildmat.2016.11.034.

[34] Cyr M, Pouhet R. The frost resistance of alkali-activated cement-based binders. In: F. Pacheco-Torgal, J.A. Labrincha, C. Leonelli, A. Palomo, P. Chindaprasirt, editors. Handbook of Alkali-Activated Cements, Mortars and Concretes. Oxford: Woodhead Publishing; 2015, p. 293-318.

[35] Bilek V, Hurta J, Done P, Zidek L. Development of alkali-activated concrete for structures - Mechanical properties and durability. Perspectives in Science 2016;7:190-4. https://doi.org/10.1016/j.pisc.2015.11.031.

[36] Fu Y, Cai L, Yonggen W. Freeze-thaw cycle test and damage mechanics models of alkali-activated slag concrete. Construction and Building Materials 2011;25(7):3144-8. https://doi.org/10.1016/j.conbuildmat.2010.12.006. 
[37] Coppola L, Coffetti D, Crotti E, Gazzaniga G, Pastore T. The Durability of One-Part Alkali-Activated Slag-Based Mortars in Different Environments. Sustainability 2020;12(9):3561. https://doi.org/10.3390/su12093561.

[38] Bilek V, Hurta J, Zidek L, Mec P. Searching for Durable and Friendly Alkali Activated Concrete for Building Elements Constructions. In: Engineering Researches and Decisions in Materials Science. Trans Tech Publications Ltd; 2015, p. 126-131.

[39] Gifford PM, Gillott JE. Freeze-Thaw Durability of Activated Blast Furnace Slag Cement Concrete. ACI Materials Journal 1996;93(3). https://doi.org/10.14359/9808.

[40] Cai L, Wang H, Fu Y. Freeze-thaw resistance of alkali-slag concrete based on response surface methodology. Construction and Building Materials 2013;49:70-6. https://doi.org/10.1016/j.conbuildmat.2013.07.045.

[41] Shahrajabian F, Behfarnia K. The effects of nano particles on freeze and thaw resistance of alkali-activated slag concrete. Construction and Building Materials 2018;176:172-8. https://doi.org/10.1016/j.conbuildmat.2018.05.033.

[42] Awoyera P, Adesina A. Durability Properties of Alkali Activated Slag Composites: Short Overview. Silicon 2020;12(4):987-96. https://doi.org/10.1007/s12633-019-00199-1.

[43] Winnefeld F, Gluth GJG, Bernal SA, Bignozzi MC, Carabba L, Chithiraputhiran S et al. RILEM TC 247-DTA round robin test: sulfate resistance, alkali-silica reaction and freeze-thaw resistance of alkali-activated concretes. Materials and Structures 2020;53(6):140. https://doi.org/10.1617/s11527-020-01562-0.

[44] Setzer MJ, Auberg A. Freeze-thaw and deicing salt resistance of concrete testing by the CDF method CDF resistance limit and evaluation of precision. Materials and Structures 1995;28:16-31. 